\title{
Changes in tobacco use at the early stage of the COVID-19 pandemic: Results of four cross-sectional surveys in Hong Kong
}

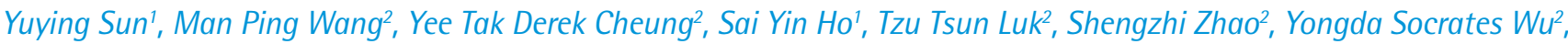 \\ Bonny Yee-Man Wong ${ }^{1,3}$, Xue Weng ${ }^{2,4}$, Jianjiu Chen ${ }^{1,5}$, Xiaoyu Zhang ${ }^{1}$, Lok Tung Leung ${ }^{1}$, Kin Yeung Chak', Tai Hing Lam
}

\begin{abstract}
INTRODuction Changes in tobacco use since the COVID-19 outbreak differed by countries and little is known about changes in the use of specific tobacco products. METHODS We analyzed data from four cross-sectional telephone/online surveys from April to June 2020 to investigate such changes since the 1st and 2nd wave outbreaks (February to April 2020) in Hong Kong. The respondents were 1595 adults ( $83.2 \%$ male) who used tobacco before the COVID-19 outbreak from our previous intervention study and surveys. We investigated the changes in tobacco use, intention to quit and quit attempts during the outbreak.

RESULTS About two-thirds (65.3\%) of respondents reported no change in overall tobacco use, while $23.1 \%$ used less (including cessation) and $11.6 \%$ used more, resulting in a net decrease of 11.5 percentage points. A greater net decrease was observed for cigarettes (14.3\% points) than heated tobacco products (HTPs, 3.3\% points) and electronic cigarettes (e-cigarettes, $2.5 \%$ points). Decreased use was mainly due to the more extended stay at home $(63.2 \%)$, health considerations (52.6\%) and mask-wearing (47.4\%), while increased use was for passing time (75.0\%) and releasing stress (46.4\%). Eight percent of cigarette, HTP and e-cigarette users reported a higher intention to quit since the pandemic outbreak. Nineteen percent of tobacco users (176/948) attempted to quit during the pandemic. Only $2.9 \%$ (46/1569) were abstinent at the time of the survey.

conclusions Overall tobacco use decreased after the first two waves of the COVID-19 outbreak in Hong Kong. A greater proportion of cigarette users decreased use than HTP and e-cigarette users. Given the different methods used in the four surveys, future studies should aim for a large and representative sample.
\end{abstract}

\author{
AFFILIATION \\ 1 School of Public Health, The \\ University of Hong Kong, Hong \\ Kong SAR, China \\ 2 School of Nursing, The University of \\ Hong Kong, Hong Kong SAR, China \\ 3 School of Nursing and Health \\ Studies, Hong Kong Metropolitan \\ University, Hong Kong SAR, China \\ 4 Institute of Advanced Studies in \\ Humanities and Social Sciences, \\ Beijing Normal University at \\ Zhuhai, Zhuhai, China \\ 5 Department of Epidemiology, \\ Mailman School of Public Health, \\ Columbia University, New York, \\ United States
}

\section{CORRESPONDENCE TO}

Sai Yin Ho. School of Public Health, The University of Hong Kong, Patrick Manson Building, North Wing, 7 Sassoon Road, Pokfulam, Hong Kong SAR, China. E-mail: syho@hku.hk

ORCID ID: https://orcid.org/ 0000-0001-9485-0273

\section{KEYWORDS}

tobacco use, smoking, tobacco products, COVID-19, surveys and questionnaires

Received: 17 September 2021

Revised: 15 December 2021

Accepted: 18 January 2022

\section{INTRODUCTION}

Although the role smoking plays in the risk of contracting COVID-19 remains controversial ${ }^{1-4}$, smoking is likely associated with more severe outcomes of COVID-19 $9^{5,6}$. Monitoring the impact of the pandemic on tobacco use behaviors is important for formulating future tobacco control policies. Some smokers have increased tobacco use during the pandemic to relieve mental distress ${ }^{7}$. The tobacco industry has opportunistically exploited the pandemic to promote alternative tobacco products ${ }^{8}$. Sales of heated tobacco products and e-cigarettes surged in the first quarter of $2020^{9}$. However, little is known about changes in the use of specific tobacco products. Some studies have examined the changes in tobacco use since the COVID-19 outbreak in the United States (US), United Kingdom (UK), Australia, Canada and other countries ${ }^{10-20}$. Some showed greater proportions of smokers who increased (19-45\%) than decreased $(13-28 \%)$ use $^{10-14}$, while some reported greater decrease $(15-73 \%)$ than increase $(14-42 \%)^{17-20}$. Although among countries and regions with the 
lowest smoking prevalence, Hong Kong still has many daily smokers $(691500 ; 10.2 \%$ of all persons aged $>15$ years $)^{21}$. The changes in tobacco use in Hong Kong during the pandemic is unclear.

In Hong Kong, the 1st wave of the COVID-19 outbreak peaked on 9 February 2020 and the 2nd wave on 27 March 2020. To contain the outbreaks, the government implemented public health interventions (e.g. working from home) and restricted public gatherings to four people since 28 March 2020 but with no lockdown. Near universal voluntary masking in public places started in early February 2020 . The first two waves were controlled with 1038 confirmed cases and four deaths by 27 April 2020. Face-mask wearing by the general public in Hong Kong was 97.5\% in February and 98.8\% in March 2020 from a telephone survey, and was $96.6 \%$ in April 2020 from an outdoor observational study ${ }^{22,23}$. The daily cases surged in early July, and the 3rd wave peaked on 30 July 2020 with 149 cases. In response, the government implemented mandatory indoor facemask regulations on 23 July $2020^{24}$. The area has been expanded to outdoor public places since 29 July 2020. Starting from 28 August 2020, people who are doing strenuous outdoor exercise or having other reasonable excuses are exempted from wearing a mask, but smoking is expressly not exempted. The 4th wave that started in late November 2020 had decreased by April 2021.

There are few reports on the changes in heated tobacco product (HTP) and electronic cigarette (e-cigarette) use since the COVID-19 outbreak. Three surveys conducted in Belgium and the US on changes in e-cigarette use in adults showed higher proportions of decreased usage or quitting (15-40\%) than increased use (10-25\%) $)^{20,25,26}$. Two surveys showed a higher proportion of increased e-cigarette use (27\%) than decreased use $(16-24 \%)^{27,28}$ in the US. A survey reported higher proportions of HTP users increased use $(31 \%)$ than decreased use or quitting (22\%) in Japan ${ }^{29}$. Changes in the use of specific tobacco products in Hong Kong have not been reported. To provide more representative and comprehensive results, we analyzed data from four cross-sectional surveys conducted from April to June 2020 in Hong Kong to investigate changes in the use of different tobacco products in adults and their reasons since the first two waves of the COVID-19 outbreak (February to April 2020). The Supplementary file gives the STROBE Statement checklist of items that should be included in reports of observational studies.

\section{METHODS}

\section{Respondents}

The four cross-sectional surveys adopted different study designs and recruited respondents from several sources. All of the surveys were conducted online or by telephone. The respondents, aged $\geq 18$ years, were all current tobacco users before the pandemic. The pre-pandemic period was defined as January 2020 or before, while the pandemic period referred to February to April 2020. All the surveys have been approved by the Institutional Review Board of the University of Hong Kong/Hospital Authority Hong Kong West Cluster (Surveys 1 and 3: UW20-238; Survey 2: UW20-326; Survey 4: UW19-169).

\section{Data collection}

The results of two of our surveys (Surveys 1 and 3) have been published, focusing respectively on the misinformation that smoking can protect against COVID-19 and the perceived benefits and harms of COVID-19 on the family ${ }^{30,31}$. The present study includes Surveys 2 and 4 with data on specific tobacco products of cigarettes, HTPs, and e-cigarettes. Other products, including cigars, hand-rolled cigarette, water pipes and pipe smoking, were not included as such data were not collected. In addition, they accounted for only $0.5 \%$ of all tobacco products used in Hong Kong ${ }^{21}$.

Survey 1 was part of the COVID-19 Health Information Survey, a cross-sectional survey of Hong Kong adults aged $\geq 18$ years, investigating COVID19-related information use, preventive behaviors and well-being. The survey was conducted from 9 to 23 April 2020 through landline telephone and mobile phone surveys ${ }^{30}$. Briefly, respondents randomly sampled from the official numbering plan for landline telecommunication services were interviewed via telephone, while those from a mobile phone panel self-administered the survey online. Among the 2212 people invited, 1501 (67.9\%) completed the survey, of whom 288 (19.2\%) were current tobacco users before the pandemic.

Survey 2 was a telephone survey conducted from 7 May to 30 June 2020, including subjects who formerly 
participated in the 'Quit to Win' project for smokers in 2018 and 2019 (organized annually by the Hong Kong Council on Smoking and Health in collaboration with us). The 'Quit to Win' project has been reported elsewhere $^{32,33}$. Among the 968 people invited, 769 (79.4\%) agreed to participate. Those who had quit smoking before the COVID-19 pandemic were excluded. Current tobacco users before the pandemic were included in the present study $(71.6 \%, 693 / 968)$.

Survey 3 was conducted from 26 to 31 May 2020 under the Jockey Club SMART Family-Link Project ${ }^{31}$. Both probability- and non-probability-based online panels through the Hong Kong Public Opinion Research Institute were invited. The probability-based panel included persons who were randomly selected in previous telephone surveys and representative of the Hong Kong population. In contrast, the nonprobability-based panel included any person in Hong Kong who volunteered to join through completing an online form. An online questionnaire was sent to 70984 adults with valid email addresses. Of those who opened the invitation emails, $24.5 \%$ (4921 of 20103) provided useable data, and 4891 remained after excluding 30 respondents without family members. A total of 362 current tobacco users before the pandemic were included.

Survey 4 was conducted online from 3 to 29 June 2020 among current tobacco users recruited at outdoor smoking hotspots from July to November 2019 (response rate: $40.0 \%, 221 / 553$ ). Three tobacco users were excluded as they had quit before the pandemic (roughly December 2019 to January 2020). A total of 218 respondents who were current tobacco users before the pandemic were included.

\section{Screening of current tobacco use}

The definition of current tobacco use was in line with that of the HKSAR Government's Thematic Household Survey ${ }^{21}$, but included alternative products such as HTPs and e-cigarettes.

Survey 1 was based on two questions: 1) 'Are you currently using any tobacco products, e.g. cigarettes, HTPs, e-cigarettes? (Yes, daily; yes, non-daily; no, I have quit; no, I never used.)'; and 2) 'Have you changed your smoking habits since the COVID-19 pandemic?'. Respondents were included if they: 1) were using tobacco daily/non-daily; or 2) had quit but answered 'have slightly/considerably decreased use' since the pandemic (quitters since the COVID-19 pandemic: quit all tobacco use at the time of survey but were a current tobacco user before the pandemic).

Survey 2 was based on two questions: 1) 'Are you currently using any tobacco products, e.g. cigarettes, HTPs, e-cigarettes? (Yes, daily; yes, non-daily; no, I have quit)'; and 2) 'How long have you quit?' They were included if they: 1) were using tobacco daily/non-daily; or 2) quitters since the COVID-19 pandemic: had quit but less than three months (if the duration was over three months, i.e. before February 2020 , the respondents were excluded as they had quit smoking before the pandemic).

Survey 3 was based on the same criteria as Survey 1 . In Survey 4 , the eligibility was checked by a retrospective question: 'In the past half-year (roughly from December 2019 to now), have you used any tobacco products?' Affirmative respondents were included.

\section{Outcomes}

The data on changes in tobacco use, intention to quit and quit attempts were extracted. Surveys 2 and 4 measured the changes in the use of cigarettes, HTPs and e-cigarettes separately. Survey 2 asked: 'During the COVID-19 pandemic, have you changed the amount of tobacco consumption?'. Answers included 'no change', 'increased', and 'decreased'. Survey 4 asked: 1) 'What was the number of tobacco products you used per day before the pandemic?'; and 2) 'What is the number of tobacco products you use per day now?'. The respondents answered the exact number of sticks for cigarettes and HTPs, and duration or number of puffs for e-cigarettes (10 minutes of use or 15 puffs were counted as one time of use). These were used to determine if tobacco consumption had increased, decreased, remained unchanged, or ceased (the numbers of all tobacco products were zero). Surveys 1 and 3 measured overall changes in tobacco use with the question: 'Since the COVID-19 pandemic, have you changed your smoking habit?'. Answers were analyzed as increased, decreased and no change. For Surveys 2 and 4, respondents reported changes in the use of specific tobacco products. The overall changes were inferred under three scenarios: 1) If the respondent was using a single product, the overall change (increase or decrease) followed the single product; 2 ) If the respondent was using 
two or more products and all had changed in the same direction, the overall change was determined accordingly; and 3) If the respondent was using two or more products with changes in a different direction, overall change was coded as missing. The difference between the proportions of respondents who increased and decreased tobacco use was calculated as the net change in percentage points.

Surveys 2 and 4 measured the changes in tobacco use at home and outdoors by asking: 1) 'Compared with pre-pandemic, have you changed your tobacco consumption at home since the pandemic?'. Answers included 'decreased', 'no change', 'increased', and 'never used tobacco at home'; and 2) 'Compared with pre-pandemic, have you changed your tobacco consumption outdoor since the pandemic?'. Answers included 'decreased', 'no change', 'increased', and 'never used tobacco outdoor'. These two surveys also measured quit attempts during the pandemic by asking: 'Since the pandemic, have you tried to quit smoking for a consecutive period of 24 hours?'. Answers included 'yes' and 'no'. Survey 4 also included the reasons of increased or decreased tobacco use (answers were 'mask-wearing', 'longer stay at home', 'health considerations', 'financial issues', 'no specific reasons', 'other reasons' for decreased use, and 'releasing stress', 'killing time', 'no specific reasons', 'other reasons' for increased use), and changes in intention to quit ("Compared with pre-pandemic, have you changed your intention to quit since the pandemic?'. Answers included 'less intention to quit', 'no change', 'more intention to quit' and 'have quit').

\section{Statistical analysis}

The data from different surveys were merged to generate appropriate combined results, including 1561 current tobacco users (73.5\% male). The analysis was conducted using SPSS 26.0 (IBM Corp, Armonk, NY). The number and percentage of categorical variables were reported. Sociodemographic characteristics were weighted by the sex and age distributions of current tobacco users of the 2019 Hong Kong adult population. However, we did not weigh sex and age by the type of tobacco products used due to a lack of data. Survey 1 adopted random sampling using landline telephone and mobile phone numbers. Survey 3 was based on a random sample from probability- and nonprobability-based online panels, while Surveys 2 and
4 used convenient samples. As a sensitivity analysis, we also examined changes in overall tobacco use based only on Surveys 1 and 3 with random samples.

\section{RESULTS}

Table 1 shows the characteristics of the four surveys. The original sample resulted in 1561 current tobacco users $(73.5 \%$ male). The weighted sample included 1595 respondents $(83.2 \%$ male) (Surveys 1 to 4 : $287,726,360$ and 222 respondents, respectively). The difference in sample size of the weighted and unweighted datasets was due to rounding. Surveys 1, 2 and 4 included 1202 respondents (aged 18-29 years: $8.1 \%$; $30-39$ years: $18.9 \%$; $40-49$ years: $21.8 \%$; $50-59$ years: $25.2 \%$; and $\geq 60$ years: $26.0 \%$ ). Survey 3 included 360 respondents (aged 18-24 years: $2.8 \%$; $25-34$ years: $13.3 \%$; $35-44$ years: $20.6 \%$; $45-54$ years: $23.3 \%$; $55-64$ years: $23.1 \%$; and $\geq 65$ years: $16.9 \%$ ). Age was missing in 35 respondents.

The results below were based on the weighted sample. Table 2 shows $65.3 \%$ of respondents reported no change in overall tobacco use, while $23.1 \%$ decreased use (including $2.9 \%$ who quit) and $11.6 \%$ increased use, resulting in a net decrease of 11.5 percentage points. If the respondents of only Survey 1 and Survey 3 were included, the net decline in overall tobacco use was 16.2 percentage points. Twenty-two percent cigarette users decreased use while only $8.1 \%$ increased use, resulting in a net decrease of 14.3 percentage points. The vast majority of users of HTP (92.3\%) and e-cigarette (91.4\%) reported no change in consumption, resulting in smaller net decreases of 3.3 and 2.5 percentage points, respectively.

Survey 4 showed that among the tobacco users who decreased use, the reduced amount were 4.5 sticks $(\mathrm{SD}=1.72 ; \mathrm{n}=19)$ of cigarettes, 5.2 sticks $(\mathrm{SD}=3.52 ; \mathrm{n}=8)$ of HTPs and 3.4 times $(\mathrm{SD}=3.68$; $\mathrm{n}=3$ ) of e-cigarette use. Among the tobacco users who increased use, the increase was 5.7 sticks $(\mathrm{SD}=3.15$; $\mathrm{n}=28)$ of cigarettes, 4.0 sticks $(\mathrm{SD}=1.83 ; \mathrm{n}=3)$ of HTPs and 3.4 times $(\mathrm{SD}=5.88 ; \mathrm{n}=3)$ of e-cigarette use.

In Survey 4, the main reasons for decreased cigarette use $(n=19)$ were longer stay at home $(63.2 \%)$, health considerations $(52.6 \%)$, mask-wearing $(47.4 \%)$ or financial issues $(15.8 \%)$. Increased cigarette use $(\mathrm{n}=28)$ was most commonly for killing time $(75.0 \%)$, releasing stress $(46.4 \%)$, no specific 
reasons $(21.4 \%)$ or other reasons (14.3\%). According to two dual users of HTPs and cigarettes who chose other reasons, HTPs were difficult to obtain during the pandemic. Survey 4 showed most users had no change in intention to quit $(86.7 \%$ cigarette users, $87.8 \%$ HTP users, and $72.0 \%$ e-cigarette users). In comparison, $8.4 \%$ cigarette users, $8.1 \%$ HTP users, and $8 \%$ e-cigarette users reported more intention to quit or have quit during the pandemic compared with pre-pandemic.

The pooled data of Surveys 2 and 4 showed that $18.6 \%$ of tobacco users (176/948) had attempted to quit (abstained from all tobacco products for at least 24 hours) during the pandemic (Survey 2: 20.5\%; Survey 4: 12.2\%). Among 176 respondents (Surveys 2 and 4$)$ who attempted to quit, $30(17.0 \%)$ were

Table 1. Characteristics of the four studies, April-June 2020, Hong Kong

\begin{tabular}{|c|c|c|c|c|}
\hline Characteristics & Survey 1 & Survey 2 & Survey 3 & Survey 4 \\
\hline Survey period & $\begin{array}{c}\text { 9-23 April } \\
n(\%)\end{array}$ & $\begin{array}{c}7 \text { May-30 June } \\
n(\%)\end{array}$ & $\begin{array}{c}\text { 26-31 May } \\
n(\%)\end{array}$ & $\begin{array}{c}\text { 3-29 June } \\
n(\%)\end{array}$ \\
\hline Sampling source/setting & $\begin{array}{l}\text { Landline telephone and } \\
\text { mobile phone numbers }\end{array}$ & $\begin{array}{l}\text { Actively approached in } \\
\text { the community from all } \\
18 \text { districts in Hong Kong } \\
\text { in } 2018 \text { and } 2019\end{array}$ & $\begin{array}{l}\text { Probability- and non- } \\
\text { probability-based online } \\
\text { panels }\end{array}$ & $\begin{array}{l}\text { Actively approached at } \\
\text { smoking hotspots on } \\
\text { streets during July to } \\
\text { November } 2019\end{array}$ \\
\hline Survey mode & Telephone \&t Online & Telephone & Online & Online \\
\hline Invited respondents, $\mathrm{n}$ & 2212 & 968 & 70984 & 553 \\
\hline Response rate & 1501 (67.9) & 769 (79.4) & $4921(6.9)$ & $221(40.0)$ \\
\hline Eligible current users, $n$ & 288 & 693 & 362 & 218 \\
\hline $\begin{array}{l}\text { Unweighted sex (\% of } \\
\text { male) }\end{array}$ & $212(73.6)$ & $604(87.2)$ & $214(59.1)$ & $140(64.2)$ \\
\hline $\begin{array}{l}\text { Unweighted age (years), } \\
\text { range: mean (SD) }\end{array}$ & $\begin{array}{l}\text { 18-29: } 44(15.3) \\
\text { 30-39: } 51(17.7) \\
\text { 40-49: } 55(19.1) \\
\text { 50-59: } 54(18.8) \\
\quad \geq 60: 84(29.2)\end{array}$ & $\begin{array}{c}\text { 18-29: } 88(13.6) \\
\text { 30-39: } 158(24.4) \\
\text { 40-49: } 161(24.8) \\
\text { 50-59: } 119(18.4) \\
\quad \geq 60: 96(14.8) \\
\text { Refused: } 26(4.0)\end{array}$ & $\begin{array}{l}\text { 18-24: } 6(1.4) \\
25-34: 68(15.6) \\
\text { 35-44: } 150(34.5) \\
\text { 45-54: } 151(34.7) \\
\text { 55-64: } 55(12.6) \\
\quad \geq 65: 5(1.1)\end{array}$ & $\begin{array}{l}\text { 18-29: } 55 \text { (24.9) } \\
\text { 30-39: } 92(41.6) \\
\text { 40-49: } 51(23.1) \\
\text { 50-59: } 21(9.5) \\
\quad \geq 60: 2(0.9)\end{array}$ \\
\hline Weighted sample & 287 & 726 & 360 & 222 \\
\hline $\begin{array}{l}\text { Weighted sex (\% of } \\
\text { male) }\end{array}$ & $237(82.6)$ & $606(83.5)$ & $299(83.1)$ & $185(83.3)$ \\
\hline $\begin{array}{l}\text { Weighted age (years), } \\
\text { range: mean (SD) }\end{array}$ & $\begin{array}{l}\text { 18-29: } 24(8.4) \\
\text { 30-39: } 54(18.8) \\
\text { 40-49: } 66(23.0) \\
\text { 50-59: } 71(24.7) \\
\quad \geq 60: 72(25.1)\end{array}$ & $\begin{array}{l}\text { 18-29: } 54(7.4) \\
\text { 30-39: } 129(17.8) \\
\text { 40-49: } 148(20.4) \\
\text { 50-59: } 177(24.4) \\
\quad \geq 60: 184(25.3) \\
\text { Refused: } 35(4.8)\end{array}$ & $\begin{array}{l}18-24: 10(2.8) \\
25-34: 48(13.3) \\
35-44: 74(20.6) \\
45-54: 84(23.3) \\
55-64: 83(23.1) \\
\geq 65: 61(16.9)\end{array}$ & $\begin{array}{l}\text { 18-29: } 19(8.6) \\
\text { 30-39: } 44(19.8) \\
\text { 40-49: } 48(21.6) \\
\text { 50-59: } 55(24.8) \\
\quad \geq 60: 57(25.7)\end{array}$ \\
\hline Type of tobacco using & Unknown & $\begin{array}{l}\text { Cigarettes: } 664 \\
\text { HTP: } 134 \\
\text { e-cigarettes: } 138\end{array}$ & Unknown & $\begin{array}{l}\text { Cigarettes: } 203 \\
\text { HTP: } 49 \\
\text { e-cigarettes: } 25\end{array}$ \\
\hline \multicolumn{5}{|l|}{ Outcomes } \\
\hline $\begin{array}{l}\text { Changes in quantity of } \\
\text { tobacco use }\end{array}$ & Overall & $\begin{array}{l}\text { Cigarettes, HTP and } \\
\text { e-cigarettes }\end{array}$ & Overall & $\begin{array}{c}\text { Cigarettes, HTP and } \\
\text { e-cigarettes }\end{array}$ \\
\hline $\begin{array}{l}\text { Changes of tobacco use } \\
\text { at home and outdoors }\end{array}$ & $\mathrm{N}$ & Y & $\mathrm{N}$ & Y \\
\hline Reasons of change & $\mathrm{N}$ & $\mathrm{N}$ & $\mathrm{N}$ & Y \\
\hline $\begin{array}{l}\text { Changes in quitting } \\
\text { intention }\end{array}$ & $\mathrm{N}$ & $\mathrm{N}$ & $\mathrm{N}$ & Y \\
\hline Quitting attempts & $\mathrm{N}$ & $Y$ & $\mathrm{~N}$ & $Y$ \\
\hline
\end{tabular}

N: not reported. Y: reported. HTP: heated tobacco product. E-cigarette: electronic cigarette. 
Table 2. Changes in tobacco use during the COVID-19 pandemic, April-June 2020, Hong Kong

\begin{tabular}{|c|c|c|c|c|}
\hline \multirow[t]{2}{*}{ Change in use } & \multicolumn{4}{|c|}{ Tobacco use } \\
\hline & $\begin{array}{c}\text { Cigarettes } \\
\text { (Surveys } 2 \& 4 \text { ) } \\
n(\%)\end{array}$ & $\begin{array}{c}\text { HTPS } \\
\text { (Surveys } 2 \text { \& 4) } \\
n(\%)\end{array}$ & $\begin{array}{c}\text { E-cigarettes } \\
\text { (Surveys } 2 \& 4) \\
n(\%)\end{array}$ & $\begin{array}{c}\text { Any tobacco product } \\
\text { (Surveys 1-4) } \\
n(\%)\end{array}$ \\
\hline \multicolumn{5}{|l|}{ Unweighted sample } \\
\hline No change & $545(66.2)$ & $173(88.3)$ & $152(87.4)$ & $950(62.1)$ \\
\hline Increased & $74(9.0)$ & $7(3.6)$ & $9(5.2)$ & $190(12.4)$ \\
\hline Decreased & $204(24.8)$ & $16(8.2)$ & $13(7.5)$ & $344(22.5)$ \\
\hline Quit* $^{*}$ & - & - & - & $46(3.0)$ \\
\hline Total & 823 & 196 & 174 & 1530 \\
\hline $\begin{array}{l}\text { Net change, } n \text { (decreased } \\
\text { percentage points) }\end{array}$ & $130(15.8)$ & $9(4.6)$ & $4(2.3)$ & $200(13.1)$ \\
\hline \multicolumn{5}{|l|}{ Weighted sample ${ }^{+}$} \\
\hline No change & $603(69.6)$ & $169(92.3)$ & 149 (91.4) & $1024(65.3)$ \\
\hline Increased & $70(8.1)$ & $4(2.2)$ & $5(3.1)$ & $182(11.6)$ \\
\hline Decreased & $194(22.4)$ & $10(5.5)$ & $9(5.5)$ & $317(20.2)$ \\
\hline Quit* & - & - & - & $46(2.9)$ \\
\hline Total & 867 & 183 & 163 & 1569 \\
\hline $\begin{array}{l}\text { Net change, } \mathrm{n} \text { (decreased } \\
\text { percentage points) }\end{array}$ & $124(14.3)$ & $6(3.3)$ & $4(2.5)$ & $181(11.5)$ \\
\hline
\end{tabular}

*For specific tobacco products, data were only available in Survey 4 and unavailable in Surveys 1-3, because the general question 'Are you currently using tobacco products, e.g. conventional cigarettes, heated tobacco products, electronic cigarettes (at the time of survey)?' could not identify from which tobacco products the respondents had quit (those who selected 'No, I quit smoking'). tThe proportions were weighted by sex and age in current tobacco users of 2019 Hong Kong adult population.

abstinent at the time of the survey. The combined data from four surveys showed only $2.9 \%$ (46/1569) were abstinent at the time of the survey. The pooled data of Surveys 2 and 4 showed that $51.9 \%$ decreased use outdoors (Survey 2: 60\% decreased, increased data not available; Survey 4: $27.5 \%$ decreased vs 3.6\% increased), while $22.1 \%$ increased use at home (Survey 2: $25.2 \%$ increased, decreased data not available; Survey $4: 12.6 \%$ increased vs $5.0 \%$ decreased). Survey 4 showed $64.1 \%$ of respondents had no changes in tobacco use both at home and outdoors, $16.4 \%$ had no changes at home but decreased use outdoors, $7.7 \%$ increased use at home but decreased use outdoors, and $3.6 \%$ increased use at home but had no changes outdoors.

\section{DISCUSSION}

We gathered the data of current smokers from four cross-sectional surveys, which were based on different sampling frames. Data from individual surveys were included for specific analyses only if the surveys had collected such data. A greater proportion of adult tobacco users reported a decrease $(23.1 \%$, including quitting) than an increase $(11.6 \%)$ in tobacco use since the first two waves of the COVID-19 pandemic, resulting in a net decrease of 11.5 percentage points. Including only the respondents from the random samples resulted in a net reduction of 16.2 percentage points. However, it is possible that the changes are natural fluctuations and may not be attributed to the pandemic. During the first two waves in Hong Kong, $18.6 \%$ of tobacco users had attempted to quit. But of those who tried to quit, only $17 \%$ were abstinent at the time of survey. One of our surveys (Survey 4) showed that the main reasons for increasing consumption were for passing time or releasing stress. Some people might have become unemployed and taken no-pay leave or worked from home since the pandemic, resulting in stress and boredom. Our previous article reported that more days stayed-at-home were associated with more depressive symptoms since the COVID-19 epidemic $^{34}$. Our results indicate the importance of providing smoking cessation services or assistance, using online approaches when face-to-face sessions are not allowed 
by social distancing regulations, together with stress coping strategies, particularly for those who had quit intention or attempts.

We observed minor changes in HTP and e-cigarette use since the COVID-19 pandemic. Some previous studies showed that e-cigarettes and HTPs helped smokers quit cigarettes, but many smokers would keep using e-cigarettes or HTPs. A Cochrane review has found a higher smoking cessation rate using nicotine e-cigarettes than nicotine replacement therapy ${ }^{35}$, but the outcome was not abstinence from all tobacco products. A trial in England found 80\% of participants who quit cigarettes using e-cigarettes were still using them at 12 months $^{36}$. A cohort study showed e-cigarette use could not help abstinence from all tobacco products ${ }^{37}$. A study in Italy has also shown that during the COVID-19 pandemic, most exclusive cigarette smokers had considered quitting, but most exclusive e-cigarette users had not ${ }^{15}$. A UK study found that current dual-use of cigarettes and e-cigarette was associated with 2.15-fold higher odds for reporting COVID-19 infection ${ }^{38}$. Many HTP and e-cigarette dual users of cigarettes were more nicotine dependent than exclusive cigarette users ${ }^{39,40}$. Our previous prospective study in Hong Kong showed HTP use was not associated with cigarette abstinence at six months ${ }^{41}$. In the present study, 9 in $10 \mathrm{HTP}$ and e-cigarette users reported no changes in use during the COVID-19 pandemic, and only two had reduced use due to difficulties in purchasing HTPs. HTPs have not been launched in Hong Kong, but some users acquired HTPs through travelling to other countries before restrictions were implemented due to the pandemic or through online purchase. The Hong Kong SAR Government has passed a new law that bans the import, manufacture, sale, distribution and advertisement of alternative smoking products (e-cigarettes, HTPs, herbal cigarettes) on 21 October 2021 with a grace period of 6 months. Monitoring and intervening against tobacco use, including HTPs and e-cigarettes, must be continued before and after enforcement of the law, especially if the pandemic remains.

We found that $22 \%$ of respondents had increased tobacco use at home, which would increase secondhand smoke exposure of family members. Our previous study showed longer stay at home was significantly associated with increased tobacco use $\mathrm{u}^{30}$.
As COVID-19 is likely to have major impacts for several years globally, compulsory mask-wearing in public places with no exemption for outdoor smoking has been implemented in Hong Kong since 29 July 2020. Monitoring the trends of tobacco consumption, indoor smoking prevalence and quitting, concerning various pandemic control measures during the pandemic are warranted.

\section{Limitations}

Our study had some limitations. The four surveys adopted different study designs and recruited respondents from various sources. The changes in tobacco use were self-reported, and data on reduced use could be subject to social desirability bias. Furthermore, the reasons for changes in tobacco use and intention to quit were only based on one survey. This would be better to be explored by a qualitative study. Lastly, the samples might not be representative of all current smokers. For example, Survey 4 recruited more young tobacco users. Surveys 3 and 4 included more female users. The response rate in Survey 3 was lower than the other surveys probably because email invitations did not involve any direct contact (voice or face-to-face) with the respondents. Although we weighted the data by sex and age using populationbased data to reduce bias, the heterogeneity among surveys was a major limitation of the present study.

\section{CONCLUSIONS}

We found a net decrease of 11.5 percentage points in tobacco use amidst the early phase of the COVID-19 pandemic. More cigarette users decreased use than HTP and e-cigarette users. Given the different methods used in the four surveys, future studies should aim for a large and representative sample. Qualitative studies are warranted to explore the mechanisms of behavioral changes to support future smoking cessation research and services.

\section{REFERENCES}

1. Hopkinson NS, Rossi N, El-Sayed Moustafa J, et al. Current smoking and COVID-19 risk: results from a population symptom app in over 2.4 million people. Thorax. 2021;76(7):714-722. doi:10.1136/thoraxjnl-2020-216422

2. Paleiron N, Mayet A, Marbac V, et al. Impact of Tobacco Smoking on the Risk of COVID-19: A Large Scale Retrospective Cohort Study. Nicotine Tob Res. 
2021;23(8):1398-1404. doi:10.1093/ntr/ntab004

3. Simons D, Shahab L, Brown J, Perski O. The association of smoking status with SARS-CoV-2 infection, hospitalization and mortality from COVID-19: a living rapid evidence review with Bayesian meta-analyses (version 7). Addiction. 2021;116(6):1319-1368. doi:10.1111/add.15276

4. Tattan-Birch H, Perski O, Jackson S, Shahab L, West R, Brown J. COVID-19, smoking, vaping and quitting: a representative population survey in England. Addiction. 2021;116(5):1186-1195. doi:10.1111/add.15251

5. Vardavas CI, Nikitara K. COVID-19 and smoking: A systematic review of the evidence. Tob Induc Dis. 2020;18(March). doi:10.18332/tid/119324

6. Patanavanich R, Glantz SA. Smoking Is Associated With COVID-19 Progression: A Meta-analysis. Nicotine Tob Res. 2020;22(9):1653-1656. doi:10.1093/ntr/ntaa082

7. Carreras G, Lugo A, Stival C, et al. Impact of COVID-19 lockdown on smoking consumption in a large representative sample of Italian adults. Tob Control. 2021. doi:10.1136/tobaccocontrol-2020-056440

8. Ramamurthi D, Chau C, Jackler RK. Exploitation of the COVID-19 pandemic by e-cigarette marketers. Tob Control. 2021;30(e1):e56-e59. doi:10.1136/tobaccocontrol-2020-055855

9. Lee JJ, Wang MP, Yang SC. Will the tobacco industry ultimately triumph in the midst of COVID-19 pandemic?: A call for nurses' action in tobacco control. Int J Nurs Stud. 2021;115:103726. doi:10.1016/j.ijnurstu.2020.103726

10. Klemperer EM, West JC, Peasley-Miklus C, Villanti AC. Change in Tobacco and Electronic Cigarette Use and Motivation to Quit in Response to COVID-19. Nicotine Tob Res. 2020;22(9):1662-1663. doi:10.1093/ntr/ntaa072

11. Jackson SE, Brown J, Shahab L, Steptoe A, Fancourt D. COVID-19, smoking, and inequalities: a cross-sectional survey of adults in the UK. medRxiv. Preprint posted online May 05, 2020. doi:10.1101/2020.04.30.20086074

12. Bommele J, Hopman P, Walters BH, et al. The doubleedged relationship between COVID-19 stress and smoking: Implications for smoking cessation. Tob Induc Dis. 2020;18(July). doi:10.18332/tid/125580

13. Sidor A, Rzymski P. Dietary Choices and Habits during COVID-19 Lockdown: Experience from Poland. Nutrients. 2020;12(6):1657. doi:10.3390/nu12061657

14. Kowitt SD, Cornacchione Ross J, Jarman KL, et al. Tobacco Quit Intentions and Behaviors among Cigar Smokers in the United States in Response to COVID-19. Int J Environ Res Public Health. 2020;17(15). doi:10.3390/ijerph17155368

15. Caponnetto P, Inguscio L, Saitta C, Maglia M, Benfatto F, Polosa R. Smoking behavior and psychological dynamics during COVID-19 social distancing and stay-at-home policies: A survey. Health Psychol Res. 2020;8(1):9124. doi:10.4081/hpr.2020.9124

16. Di Renzo L, Gualtieri P, Pivari F, et al. Eating habits and lifestyle changes during COVID-19 lockdown: an Italian survey. J Transl Med. 2020;18(1):229. doi:10.1186/s12967-020-02399-5

17. Rigotti NA, Chang Y, Regan S, et al. Cigarette Smoking and Risk Perceptions During the COVID-19 Pandemic Reported by Recently Hospitalized Participants in a Smoking Cessation Trial. J Gen Intern Med. 2021;36(12):37863793. doi:10.1007/s11606-021-06913-3

18. Siddiqi K, Siddiqui F, Khan A, et al. The Impact of COVID-19 on Smoking Patterns in Pakistan: Findings From a Longitudinal Survey of Smokers. Nicotine Tob Res. 2021;23(4):765-769. doi:10.1093/ntr/ntaa207

19. Gravely S, Craig LV, Cummings KM, et al. Smokers' cognitive and behavioural reactions during the early phase of the COVID-19 pandemic: Findings from the 2020 ITC Four Country Smoking and Vaping Survey. PLoS One. 2021;16(6):e0252427. doi:10.1371/journal.pone.0252427

20. Adriaens K, Van Gucht D, Van Lommel S, Baeyens F. Vaping during the COVID-19 lockdown period in Belgium. BMC Public Health. 2021;21:1613. doi:10.1186/s12889-021-11637-4

21. Census and Statistics Department Hong Kong Special Administrative Region. Thematic Household Survey: Report No. 70. Census and Statistics Department Hong Kong Special Administrative Region; 2020. Accessed October 29, 2020. https://www.statistics.gov.hk/pub/ B11302702020XXXXB0100.pdf

22. Cowling BJ, Ali ST, Ng TWY, et al. Impact assessment of non-pharmaceutical interventions against coronavirus disease 2019 and influenza in Hong Kong: an observational study. Lancet Public Health. 2020;5(5):e279-e288. doi:10.1016/S2468-2667(20)30090-6

23. Cheng VC, Wong SC, Chuang VW, et al. The role of community-wide wearing of face mask for control of coronavirus disease 2019 (COVID-19) epidemic due to SARS-CoV-2. J Infect. 2020;81(1):107-114. doi:10.1016/j.jinf.2020.04.024

24. The Government of the Hong Kong Special Administrative Region. Useful information. 2020. Accessed August 7, 2020. https://www.coronavirus.gov.hk/eng/index. html\#Useful_Information

25. Gaiha SM, Lempert LK, Halpern-Felsher B. Underage Youth and Young Adult e-Cigarette Use and Access Before and During the Coronavirus Disease 2019 Pandemic. JAMA Netw Open. 2020;3(12):e2027572. doi:10.1001/jamanetworkopen.2020.27572

26. Sharma P, Ebbert JO, Rosedahl JK, Philpot LM. Changes in substance use among young adults during a respiratory disease pandemic. SAGE Open Med. 2020;8:2050312120965321. doi:10.1177/2050312120965321

27. Streck JM, Kalkhoran S, Bearnot B, et al. Perceived risk, attitudes, and behavior of cigarette smokers and nicotine vapers receiving buprenorphine treatment for opioid use disorder during the COVID-19 
pandemic. Drug Alcohol Depend. 2021;218:108438. doi:10.1016/j.drugalcdep.2020.108438

28. White AM, Li D, Snell LM, et al. Perceptions of tobacco product-specific COVID-19 risk and changes in tobacco use behaviors among smokers, e-cigarette users, and dual users. Nicotine Tob Res. 2021;23(9):1617-1622. doi:10.1093/ntr/ntab053

29. Koyama S, Tabuchi T, Okawa S, et al. Changes in Smoking Behavior Since the Declaration of the COVID-19 State of Emergency in Japan: A Cross-sectional Study From the Osaka Health App. J Epidemiol. 2021;31(6):378-386. doi:10.2188/jea.JE20200533

30. Luk TT, Zhao S, Weng X, et al. Exposure to health misinformation about COVID-19 and increased tobacco and alcohol use: a population-based survey in Hong Kong. Tob Control. 2020;30(6):696-699. doi:10.1136/tobaccocontrol-2020-055960

31. Wong BY, Lam TH, Lai AY, Wang MP, Ho SY. Perceived Benefits and Harms of the COVID-19 Pandemic on Family Well-Being and Their Sociodemographic Disparities in Hong Kong: A Cross-Sectional Study. Int J Environ Res Public Health. 2021;18(3):1217. doi:10.3390/ijerph18031217

32. Weng X, Wang MP, Li HCW, et al. Effects of active referral combined with a small financial incentive on smoking cessation: study protocol for a cluster randomised controlled trial. BMJ Open. 2020;10(10):e038351. doi:10.1136/bmjopen-2020-038351

33. Wang MP, Luk TT, Wu Y,et al. Chat-based instant messaging support integrated with brief interventions for smoking cessation: a community-based, pragmatic, cluster-randomised controlled trial. Lancet Digit Health. 2019;1(4):e183-e192. doi:10.1016/S2589-7500(19)30082-2

34. Zhao SZ, Wong JYH, Wu Y, Choi EPH, Wang MP, Lam TH. Social Distancing Compliance under COVID-19 Pandemic and Mental Health Impacts: A Population-Based Study. Int J Environ Res Public Health. 2020;17(18):6692. doi:10.3390/ijerph17186692

35. Hartmann-Boyce J, McRobbie H, Lindson N, et al. Electronic cigarettes for smoking cessation. Cochrane Database Syst Rev. 2020;10(10):CD010216. doi:10.1002/14651858.CD010216.pub4

36. Hajek P, Phillips-Waller A, Przulj D, et al. A Randomized Trial of E-Cigarettes versus Nicotine-Replacement Therapy. N Engl J Med. 2019;380(7):629-637. doi:10.1056/NEJMoa1808779

37. Sweet L, Brasky TM, Cooper S, et al. Quitting Behaviors Among Dual Cigarette and E-Cigarette Users and Cigarette Smokers Enrolled in the Tobacco User Adult Cohort. Nicotine Tob Res. 2019;21(3):278-284. doi:10.1093/ntr/nty222

38. Chen DTH, Kyriakos CN. Cigarette and E-Cigarettes Dual Users, Exclusive Users and COVID-19: Findings from Four UK Birth Cohort Studies. Int J Environ Res Public Health. 2021;18(8). doi:10.3390/ijerph18083935

39. Sutanto E, Miller C, Smith DM, et al. Concurrent
Daily and Non-Daily Use of Heated Tobacco Products with Combustible Cigarettes: Findings from the 2018 ITC Japan Survey. Int J Environ Res Public Health. 2020;17(6):2098. doi:10.3390/ijerph17062098

40. Rostron BL, Schroeder MJ, Ambrose BK. Dependence symptoms and cessation intentions among US adult daily cigarette, cigar, and e-cigarette users, 2012-2013. BMC Public Health. 2016;16(1):814. doi:10.1186/s12889-016-3510-2

41. Luk TT, Weng X, Wu YS, et al. Association of heated tobacco product use with smoking cessation in Chinese cigarette smokers in Hong Kong: a prospective study. Tob Control. 2020;30(6):653-659. doi:10.1136/tobaccocontrol-2020-055857

\section{CONFLICTS OF INTEREST}

The authors have each completed and submitted an ICMJE form for disclosure of potential conflicts of interest. The authors declare that they have no competing interests, financial or otherwise, related to the current work. M.P. Wang, S.Y. Ho, T.H. Lam, Y.T.D. Cheung, J. Chen and L.T. Leung report that since the initial planning of the work they received funding from Health and Medical Research Fund (Grant: TCHKU) for conducting Survey 4. M.P. Wang, S.Y. Ho and T.H. Lam report that they received funding from the Hong Kong Jockey Club Charities Trust for conducting Survey 3. L.T. Leung reports that in the past 36 months was employed by The Hong Kong Council on Smoking and Health.

\section{FUNDING}

Survey 3 under Jockey Club Smart Family-Link Project was supported by the Hong Kong Jockey Club Charities Trust. Survey 4 was supported by the Health and Medical Research Fund (Grant: TC-HKU). Surveys 1 and 2 were self-initiated without external funding. The funder had no role in study design, data collection/analysis/interpretation or manuscript preparation.

\section{ETHICAL APPROVAL AND INFORMED CONSENT}

The study was approved by the Institutional Review Board of the University of Hong Kong/Hospital Authority Hong Kong West Cluster (Surveys 1 and 3: UW20-238, date of approval: 30 March 2020; Survey 2: UW20-326, date of approval: 28 April 2020; Survey 4: UW19-169, date of approval: 20 May 2020). Verbal or electronic consent was obtained. Completion of the questionnaire was taken as informed consent.

\section{DATA AVAILABILITY}

The data supporting this research are available from the authors on reasonable request.

\section{AUTHORS' CONTRIBUTIONS}

Concept or design: All authors. Acquisition of data: YS, TL, SZ, YSW, BYMW, XW, JC, XZ, LTL and KYC. Analysis or interpretation of data: All authors. Drafting of the article: YS. Critical revision for important intellectual content: MPW, YTDC, SYH and THL. All authors have full access to the data, have read and approved the final version for publication.

\section{PROVENANCE AND PEER REVIEW}

Not commissioned; externally peer reviewed. 